\title{
Clinical Trials in Metastatic Uveal Melanoma: Immunotherapy
}

\author{
Marlana Orloff \\ Sidney Kimmel Cancer Center, Thomas Jefferson University, Philadelphia, PA, USA
}

\section{Keywords}

Uveal melanoma $\cdot$ Immunotherapy $\cdot$ Immune checkpoint inhibitor Vaccine $\cdot \mathrm{T}$ cell

\begin{abstract}
Background: Uveal melanoma (UM) is a rare subtype of melanoma that generally has a poor prognosis once it has metastasized. Clinical trials evaluating immune checkpoint inhibitors (ICls) in UM have demonstrated response rates lower than those seen in cutaneous melanoma. Despite lower efficacy demonstrated in initial ICl studies, there are a number of ongoing clinical trials investigating novel immunotherapy approaches in UM. Summary: This review aims to summarize important ongoing clinical trials investigating immunotherapeutic approaches in UM and previous trials that have evaluated a number of immunologic interventions. A thorough clinical trial investigation was conducted through clinicaltrials.gov using the disease search terms "uveal melanoma" and "ocular melanoma," excluding nonimmunotherapy-related trials. Here, we report on $\mathrm{ICl}$, vaccine, adoptive $T$ cells, and combination immunotherapy trials in UM. Key Messages: There is an increasing effort in the search for new, effective therapies for this difficult-to-treat
\end{abstract}

disease, with immunotherapeutic approaches being of particular interest. Increasing knowledge of UM biology and development of new biomarkers will direct future drug development and trial design.

(c) 2021 S. Karger AG, Basel

\section{Introduction}

Uveal melanoma (UM) is the most common primary intraocular malignancy in adults, with approximately 8,000 new cases worldwide per year [1]. The prognosis for patients with advanced UM remains bleak, with up to $50 \%$ developing metastatic disease, typically in the liver via the hematogenous route $[1,2]$. Once metastatic, overall survival (OS) is limited, often reported as $<12$ months $[2,3]$.

Unfortunately, while poor outcomes are common for patients with UM, there is currently no globally recognized standard of care [4]. Institutions often adhere to individual algorithms for therapy based on their expertise and resources. In the absence of approved, disease-specific therapies, enrollment of UM patients on clinical trials has been critical [4]. Furthermore, there are ongoing 
misperceptions about how UM differs from other melanoma subtypes, specifically the more common cutaneous melanoma (CM). Understanding the differences in biology and molecular characteristics of UM and CM is imperative for appropriate management and treatment selection.

This review will focus on the current status of immunotherapy treatment strategies and clinical trials for metastatic UM (MUM). Immunotherapies have been revolutionary in cancer treatment and hold promise as effective therapies for patients with UM and other difficult-totreat tumor types. There is a rising number of immunotherapy clinical trials for patients with UM/MUM, including checkpoint inhibition, vaccines, and T-cell therapies. Please note that many of the therapies included in the clinical trials mentioned here are investigational agents, whose safety and efficacy may not have been established in larger and later-phase clinical trials.

\section{Summary of Prior Studies and Ongoing Clinical Trials}

\section{Methods}

Clinical trial information was downloaded from clinicaltrials.gov using the disease search terms "uveal melanoma" and "ocular melanoma" (July 24, 2020). Adjuvant trials and trials not including immunotherapies were excluded, and trials were combined from each search and grouped according to immunotherapy class: checkpoint inhibition, vaccines, adoptive T-cell therapy, and bispecific T-cell redirection. Trials were then ordered in terms of "status," then "phase" and start date of the "trial period." Tables 1-3 include trials that are "not yet recruiting," "recruiting," "active but not recruiting," "enrolling by invitation," and "suspended," excluding trials that are "completed," "withdrawn," "terminated," or "no longer available." However, if any "completed," "withdrawn," "terminated," or "no longer available" trials had data specifically for UM patients available, then these data were reported in the text summary.

\section{Immune Checkpoint Inhibitors}

Immune checkpoint inhibitors (ICIs) are monoclonal antibodies that inhibit interactions between immune checkpoint proteins, such as programmed death-1 (PD1)/PD-ligand 1 (PD-L1) and cytotoxic T-lymphocyte antigen-4 (CTLA-4)/B7-1/B7-2, enabling $\mathrm{T}$ cells to recognize and attack cancer cells. ICIs, such as nivolumab, pembrolizumab (both PD-1 inhibitors), and ipilimumab (a CTLA-4 inhibitor), have positively transformed the clinical management of CM patients, with monotherapy achieving response rates of approximately 10-45\% [17], and combination therapy (most commonly ipilimumab with nivolumab) attaining response rates of 58\% [18].

Conversely, responses to ICIs in MUM have been disappointing, possibly due to the lower mutagenicity, immunogenicity, and PD-L1 expression levels of UM compared with CM $[2,19,20]$. MUM responses to ICI monotherapy are around $0-7 \%$, with short median progression-free survival (PFS) and OS values of about $2-3$ months and up to approximately 1 year, respectively [20-24]. However, preliminary results from a terminated (due to slow accrual), phase II, single-arm, multicenter, 3-year, prospective study of pembrolizumab monotherapy (NCT02359851) were encouraging, although only in a total of 5 patients - all with MUM. One patient experienced complete response and 2 experienced stable disease; clinical benefit was associated with limited hepatic disease burden [25]. A larger, retrospective, phase IV trial, aiming to enroll 100 patients by invitation, will investigate the activity of nivolumab or pembrolizumab in MUM (NCT03964298), detailed later. ICI trials are presented in Table 1.

ICI combination therapy has yielded results inferior to those seen in CM [20]. Of three retrospective studies of combined PD-1 inhibitor and ipilimumab, one was limited to 15 patients and reported a $16.7 \%$ response rate and PFS of only 2.8 months [20,22]. The two larger studies described similar results; one was in 64 patients across 16 centers and reported a $15.6 \%$ response rate, PFS of only 3 months, and an OS of 16.1 months [26], and the other was in 89 patients across 14 centers and reported an $11.6 \%$ response rate, PFS of 2.7 months, and OS of 15 months [27]. The ongoing GEM1402 phase II, single-arm, multicenter trial (NCT02626962), studying nivolumab/ipilimumab in 50 previously untreated patients with MUM, reported a $12 \%$ response rate and median PFS and OS of 3.3 and 12.7 months, respectively [5]. A single-arm, singleinstitution, expanded access program (CheckMate218 trial [NCT02186249]) assessed nivolumab/ipilimumab therapy in metastatic melanoma; in a small cohort of $6 / 64$ patients (9\%) with UM, none responded, and of $47 / 64$ patients (73\%) with CM, 28/44 (64\%) responded [20, 28]. However, an ongoing phase II, single-arm, single-institution study investigating nivolumab/ipilimumab demonstrated more encouraging results in 30 treatment-naïve or previously treated patients with MUM(NCT01585194), with a response rate of $17 \%$ and median PFS and OS of 6 and 19.1 months, respectively [6]. 
Table 1. Clinical trials involving checkpoint inhibition [5-14]

\begin{tabular}{|c|c|c|c|c|c|}
\hline NCT04463368 & $\begin{array}{l}\text { Isolated hepatic perfusion in combination } \\
\text { with ipilimumab + nivolumab in patients } \\
\text { with UM metastases (SCANDIUM II) }\end{array}$ & $\begin{array}{l}\text { Not yet } \\
\text { recruiting }\end{array}$ & I & $\begin{array}{l}\text { Sahlgrenska University Hospital, } \\
\text { Sweden; Bristol-Myers Squibb }\end{array}$ & $\begin{array}{l}\text { January } 2021- \\
\text { June } 2023\end{array}$ \\
\hline NCT02858869a $[8,9]$ & $\begin{array}{l}\text { Pembrolizumab + stereotactic radiosurgery } \\
\text { for melanoma (including ocular) or NSCLC } \\
\text { brain metastases }\end{array}$ & Recruiting & I & $\begin{array}{l}\text { Emory University; Merck Sharp \& } \\
\text { Dohme Corp. }\end{array}$ & $\begin{array}{l}\text { October 2016- } \\
\text { October } 2021\end{array}$ \\
\hline NCT03652077 & $\begin{array}{l}\text { INCAGN02390 in select advanced } \\
\text { malignancies, including MUM }\end{array}$ & Recruiting & I & Incyte Corporation & $\begin{array}{l}\text { August 2018- } \\
\text { January } 2021\end{array}$ \\
\hline NCT03922880 & $\begin{array}{l}\text { Nivolumab + ipilimumab + arginine } \\
\text { deprivation (ADI-PEG 20) in MUM }\end{array}$ & Recruiting & I & $\begin{array}{l}\text { Memorial Sloan Kettering Cancer } \\
\text { Center }\end{array}$ & $\begin{array}{l}\text { April 2019- } \\
\text { April } 2020\end{array}$ \\
\hline NCT04283890 & $\begin{array}{l}\text { PHP }+ \text { immunotherapy (ipilimumab + } \\
\text { nivolumab) in MUM (CHOPIN) }\end{array}$ & Recruiting & $\mathrm{I} / \mathrm{II}$ & $\begin{array}{l}\text { HW Kapiteijn, Leiden University } \\
\text { Medical Center }\end{array}$ & $\begin{array}{l}\text { December 2019- } \\
\text { December } 2024\end{array}$ \\
\hline NCT02831933 [14] & $\begin{array}{l}\text { Radiation (SBRT) + gene therapy (ADV/ } \\
\text { HSV-tk) + valacyclovir before nivolumab } \\
\text { for metastatic NSCLC + UM (ENSIGN) }\end{array}$ & Recruiting & II & $\begin{array}{l}\text { Eric Bernicker, MD, The Methodist } \\
\text { Hospital System }\end{array}$ & $\begin{array}{l}\text { February } 2017- \\
\text { June } 2022\end{array}$ \\
\hline NCT03070392 & $\begin{array}{l}\text { Tebentafusp (IMCgp 100) versus } \\
\text { investigator choice (dacarbazine, } \\
\text { ipilimumab, or pembrolizumab) in MUM }\end{array}$ & Recruiting & II & Immunocore Ltd. & $\begin{array}{l}\text { October 2017- } \\
\text { March } 2023\end{array}$ \\
\hline NCT03964298 & $\begin{array}{l}\text { Nivolumab + pembrolizumab in MUM } \\
\text { (imMUno) }\end{array}$ & $\begin{array}{l}\text { Enrolling by } \\
\text { invitation }\end{array}$ & IV & Institut Curie & $\begin{array}{l}\text { November } 2016- \\
\text { December } 2019\end{array}$ \\
\hline NCT03068624 [10] & $\begin{array}{l}\text { Autologous CD8+ SLC45A2-specific T } \\
\text { lymphocytes + cyclophosphamide, IL-2 } \\
\text { (aldesleukin) + ipilimumab in MUM }\end{array}$ & $\begin{array}{l}\text { Active, not } \\
\text { recruiting }\end{array}$ & I & MD Anderson Cancer Center; NCI & $\begin{array}{l}\text { September } 2017- \\
\text { September } 2021\end{array}$ \\
\hline NCT01585194 [6] & Nivolumab + ipilimumab in MUM & $\begin{array}{l}\text { Active, not } \\
\text { recruiting }\end{array}$ & II & MD Anderson Cancer Center; NCI & $\begin{array}{l}\text { November } 2012- \\
\text { November } 2019\end{array}$ \\
\hline NCT02626962 [5] & $\begin{array}{l}\text { Nivolumab + ipilimumab in previously } \\
\text { untreated MUM (GEM1402) }\end{array}$ & $\begin{array}{l}\text { Active, not } \\
\text { recruiting }\end{array}$ & II & $\begin{array}{l}\text { Grupo Español Multidisciplinar de } \\
\text { Melanoma; Bristol-Myers Squibb }\end{array}$ & $\begin{array}{l}\text { April 2016- } \\
\text { September } 2020\end{array}$ \\
\hline NCT02697630 [13] & $\begin{array}{l}\text { Pembrolizumab + entinostat to treat MUM } \\
\text { (PEMDAC) }\end{array}$ & $\begin{array}{l}\text { Active, not } \\
\text { recruiting }\end{array}$ & II & $\begin{array}{l}\text { Vastra Gotaland Region; Merck } \\
\text { Sharp \& Dohme Corp; Syndax } \\
\text { Pharmaceuticals }\end{array}$ & $\begin{array}{l}\text { February } 2018- \\
\text { August } 2023\end{array}$ \\
\hline
\end{tabular}

ADI-PEG 20, pegylated arginine deiminase; ADV/HSV-tk, adenovirus-mediated expression of herpes simplex virus thymidine kinase; CD, cluster of differentiation; IL-2, interleukin-2; IT, intrathecal; IV, intravenous; MM, metastatic melanoma; MUM, metastatic uveal melanoma; NCI, National Cancer Institute; NSCLC, non-small cell lung cancer; PHP, percutaneous hepatic perfusion; SBRT, stereotactic body radiation therapy; SLC45A2, solute carrier family 45 member 2; UM, uveal melanoma. ${ }^{\text {a }}$ Trials that have data published; however, UM patient data are not called out. 
Table 2. Clinical trials involving vaccines

\begin{tabular}{lllll}
\hline $\begin{array}{l}\text { NCT No. } \\
\text { (reference) }\end{array}$ & Trial & Status & Phase & Sponsor/collaborators \\
\hline NCT04335890 & $\begin{array}{l}\text { IKKb-matured, RNA-loaded } \\
\text { dendritic cells for metastasized } \\
\text { UM }\end{array}$ & $\begin{array}{l}\text { Not yet } \\
\text { recruiting }\end{array}$ & I & $\begin{array}{l}\text { Hasumi International Research Foundation; } \\
\text { Beatrice Schuler-Thurner, PhD, University } \\
\text { Hospital Erlangen }\end{array}$ \\
\hline
\end{tabular}

UM, uveal melanoma.

Table 3. Clinical trials involving T-cell therapies $[10,15,16]$

\begin{tabular}{|c|c|c|c|c|c|}
\hline NCT No. (reference) & Trial & Status & Phase & Sponsor/collaborators & Trial period \\
\hline NCT03635632 & $\begin{array}{l}\text { C7R-GD2.CART cells for patients with } \\
\text { relapsed or refractory neuroblastoma and } \\
\text { other GD2-positive cancers (GAIL-N) }\end{array}$ & Recruiting & I & $\begin{array}{l}\text { Naylor College of Medicine; Center for } \\
\text { Cell and Gene Therapy, Baylor College } \\
\text { of Medicine; The Methodist Hospital } \\
\text { System; Cancer Prevention Research } \\
\text { Institute of Texas }\end{array}$ & $\begin{array}{l}\text { April 2019- } \\
\text { December } 2037\end{array}$ \\
\hline NCT03070392 & $\begin{array}{l}\text { Tebentafusp (IMCgp100) versus } \\
\text { investigator choice (dacarbazine, } \\
\text { ipilimumab, or pembrolizumab) in MUM }\end{array}$ & Recruiting & II & Immunocore Ltd. & $\begin{array}{l}\text { October 2017- } \\
\text { March } 2023\end{array}$ \\
\hline NCT03467516 & Adoptive transfer TILs for MUM & Recruiting & II & Udai Kammula; University of Pittsburgh & $\begin{array}{l}\text { May 2018- } \\
\text { December } 2021\end{array}$ \\
\hline NCT03068624 [10] & $\begin{array}{l}\text { Autologous CD8+ SLC45A2-specific T } \\
\text { lymphocytes + cyclophosphamide, IL-2 } \\
\text { (aldesleukin) + ipilimumab in MUM }\end{array}$ & $\begin{array}{l}\text { Active, not } \\
\text { recruiting }\end{array}$ & I & MD Anderson Cancer Center; NCI & $\begin{array}{l}\text { September } 2017 \\
\text { September } 2021\end{array}$ \\
\hline NCT02654821 [16] & $\begin{array}{l}\text { TCR gene therapy (TCR-transduced T } \\
\text { cells) in MM (including ocular melanoma) }\end{array}$ & $\begin{array}{l}\text { Active, not } \\
\text { recruiting }\end{array}$ & $\mathrm{I} / \mathrm{II}$ & The Netherlands Cancer Institute & $\begin{array}{l}\text { March 2012- } \\
\text { January } 2020\end{array}$ \\
\hline NCT02570308 [15] & $\begin{array}{l}\text { Intrapatient escalation dosing with } \\
\text { tebentafusp (IMCgp 100) in MUM patients }\end{array}$ & $\begin{array}{l}\text { Active, not } \\
\text { recruiting }\end{array}$ & $\mathrm{I} / \mathrm{II}$ & Immunocore Ltd. & $\begin{array}{l}\text { February 2016- } \\
\text { January } 2021\end{array}$ \\
\hline NCT02743611 & $\begin{array}{l}\text { BPX-701 (a genetically modified } \\
\text { autologous T-cell product incorporating a } \\
\text { HLA-A2-restricted PRAME-directed TCR } \\
\text { and a rimiducid-inducible safety switch) in } \\
\text { previously treated AML/MDS or MUM }\end{array}$ & $\begin{array}{l}\text { Active, not } \\
\text { recruiting }\end{array}$ & $\mathrm{I} / \mathrm{II}$ & Bellicum Pharmaceuticals & $\begin{array}{l}\text { April 2017- } \\
\text { July } 2020\end{array}$ \\
\hline
\end{tabular}

AML, acute myeloid leukemia; CD, cluster of differentiation; HLA, human leukocyte antigen; IL-2, interleukin-2; MDS, myelodysplastic syndrome; MM, metastatic melanoma; MUM, metastatic uveal melanoma; NCI, National Cancer Institute; PRAME, preferentially expressed antigen in melanoma; SLC45A2, solute carrier family 45 member 2 ; TCR, T-cell receptor; TIL, tumor-infiltrating lymphocyte.

The potential of durability of response with ICIs should also be considered. A recent report presented a case of complete metabolic response lasting 22 months post-treatment with ipilimumab and nivolumab [29]. The aforementioned retrospective analysis in 64 patients with MUM or unresectable UM treated with ipilimumab/ PD-1 inhibitor reported a $15.6 \%$ response rate; however, median duration of response was a promising 25.5 months (range: 9-65) [26].

In predicting patient responses to ICIs, there is encouraging evidence that methyl-CpG binding domain protein 4 (MBD4)-deficient tumors may be sensitive to checkpoint inhibitors, and therefore MBD4 is a potential predictor of ICI response for therapy in the future. Rodrigues et al. [30] reported that in a series of 102 patients with MUM, 2 (2\%) were identified as having germline deleterious frameshift deletions of MBD4, of which one was an outlier patient with an exceptionally high sensitivity to pembrolizumab.

Although, to date, most immunotherapy trials in MUM have evaluated CTLA-4- and PD-1/PD-L1-based therapies, there is ongoing research into new ICI tumor 
targets, such as T-cell immunoglobulin and mucin domain-3 (TIM-3) and lymphocyte-activation gene 3 (LAG3 ) to use for the development of monotherapies or addon agents. TIM-3, an inhibitory receptor involved in immune tolerance, is expressed in many human cancers and infiltrating immune cells. INCAGN02390 is a novel, antagonistic antibody specific for TIM-3 that is being evaluated in a phase I, single-arm trial (NCT03652077) with an accrual goal of 41 patients with advanced malignancies, including MUM [31]. Though there are no current LAG3 trials specific for the MUM population, there is a rationale for this target, and trials are likely forthcoming [32].

Clinical trials are also underway for ICIs combined with liver-directed therapy in an effort to enhance their anticancer toxicity. It is postulated that tumor death and antigen presentation, driven by liver-directed therapy, could augment a response to combination or subsequent immunotherapy. Interim results for NCT02913417, a phase I/II, single-arm, multicenter trial, have shown that treating MUM metastatic to the liver with radioembolization with yttrium90, followed by ipilimumab and nivolumab is a feasible treatment option. Of 13 patients, 10 received both yttrium 90 and immunotherapy, and an overall response was recorded for $23 \%$ of patients (3/13), who remained stable for $>5$ months, and median PFS and OS values were reported as 6.2 and $>11$ months, respectively [7]. A phase II, single-arm, single-center trial will investigate ipilimumab and nivolumab with immunoembolization in 35 patients with MUM (NCT03472586). There are also two trials investigating ipilimumab/ nivolumab combined with selective administration of chemotherapy (melphalan) to the liver via percutaneous hepatic perfusion in MUM: CHOPIN (NCT04283890), a phase I/II, randomized, three-arm, single-center study in an estimated 88 patients with MUM, and SCANDIUM II (NCT04463368), a phase I, randomized, multicenter study, in an estimated 18 patients with MUM.

Additionally, there are trials combining standard ICIs with alternative agents and other immunotherapy modalities. For example, PEMDAC (NCT02697630) is a phase II, single-arm, multicenter trial evaluating pembrolizumab in combination with the epigenetic therapy regulator entinostat, a benzamide histone deacetylase inhibitor, in 29 patients; $90 \%$ with MUM. Interim results showed that of 29 patients, 3 achieved a partial response to give an overall response of $10 \%, 9$ patients (31\%) had stable disease, and median OS was 11.5 months [33]. There are also two small phase I trials for advanced UM: one single-arm, single-institution study investigating nivolumab/ipilimumab combined with arginine deple- tion using pegylated arginine deiminase (ADI-PEG 20) in 9 patients with MUM (NCT03922880) and a second, recently completed, single-arm, multicenter trial (VLA024 CLEVER) that investigated ipilimumab with oncolytic virus CAVATAK $®$ in 11 patients with MUM (NCT03408587). Furthermore, there are two other recruiting trials studying ICIs in combination with forms of radiotherapy (NCT02858869 and NCT03850691) and gene therapy (NCT02831933). There is also a phase I, single-arm, single-center study aiming to investigate ipilimumab combined with autologous tumor-infiltrating lymphocyte (TIL) transfer in 19 patients with MUM (NCT03068624, see 'Adoptive T-cell therapies' section), three completed trials of ICIs in combination with vaccine therapy that include patients with MUM (NCT00025181, NCT00032045, and NCT00084656), and a phase I/II trial that reported poor results for ipilimumab with interleukin-2 (IL-2) therapy in metastatic melanoma, including UM (NCT00058279) [34].

Another ICI trial of note is a recently completed phase II, two-arm, randomized, multicenter trial evaluating ipilimumab versus nab-paclitaxel and bevacizumab as firstline therapy in 24 patients with stage IV melanoma, including MUM, that cannot be surgically removed (NCT02158520); no data have yet been reported. Additional recruiting trials include a phase I, single-arm, single-center study evaluating intrathecal and intravenous delivery of nivolumab in an estimated 30 patients with leptomeningeal melanoma, including patients with MUM (NCT03025256), and a phase II, randomized, twoarm, multicenter study investigating dacarbazine, ipilimumab, or pembrolizumab versus the new bispecific T-cell receptor (TCR) redirection therapeutic, tebentafusp, in MUM (NCT03070392), discussed later.

\section{Vaccines}

Cancer vaccines are designed to stimulate the immune system to better recognize tumor-associated antigens on cancer cells and destroy them, and there has been a concerted effort to evaluate vaccines in UM. Dendritic cells can be used in vaccine-based therapies; these are antigenpresenting cells with the ability to activate naïve antigenspecific $\mathrm{T}$ cells to stimulate immune activity against tumors. There is a new phase I, single-arm, single-center trial, not yet recruiting, which will evaluate IKKb-matured, dendritic cells loaded with RNA coding for tumor mRNA, defined tumor-associated antigens and driver mutations, in the treatment of MUM (NCT04335890). This vaccine trial is presented in Table 2. 


\section{T-Cell-Based Approaches}

It has been postulated that MUM may demonstrate innate resistance to currently available immunotherapies due to low mutational burden, as well as low PD-L1 expression and paucity of intratumoral $\mathrm{T}$ cells, especially in hepatic metastases [20,35]. A recent study demonstrated that cytotoxic (cluster of differentiation 8-positive [CD8+]) TILs are mostly located peritumorally at the tumor/normal liver interface rather than within the tumors [20,36]. Redirection of patient T cells into MUM tumors is another strategy being pursued to treat MUM. Adoptive T-cell therapies, such as TIL therapy and engineered TCR T cells, have been considered, as well as the novel

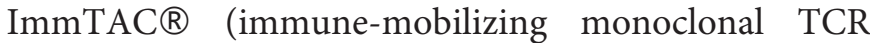
against cancer) molecule, tebentafusp. T-cell-based approach trials are presented in Table 3.

\section{Adoptive T-Cell Therapies}

Adoptive $\mathrm{T}$-cell therapies involve removing $\mathrm{T}$ cells from a cancer patient, isolating and expanding them ex vivo, and then reinfusing them back into the patient in an attempt to enhance their immune system to more efficiently attack the cancer. The $\mathrm{T}$ cells may be extracted from a harvested tumor or removed from peripheral circulation through apheresis. An example is TIL therapy, which has shown promise in treating MUM in a phase II, two-arm, single-center trial (NCT01814046). Twenty patients with MUM were treated with lympho-depleting conditioning chemotherapy, followed by infusion of autologous TILs with high-dose IL-2. An interim analysis demonstrated an overall response rate of $35 \%$ in terms of objective tumor regression. Remarkably, liver metastatic tumors completely regressed for 1 patient, with no signs of recurrence 21 months after therapy [37]. This trial was terminated in 2018 with no further data on OS or durability of response. A larger-scale, phase II, single-arm, single-center study is currently recruiting to evaluate a nonmyeloablative, lympho-depleting preparative regimen consisting of fludarabine and cyclophosphamide, followed by infusion of autologous TILs and high-dose IL-2 in 59 patients with MUM (NCT03467516).

Autologous tumor antigen-specific T cells can be generated and expanded from peripheral blood, and patient T cells can also be modified so they are better able to target a particular cancer antigen. A phase I, single-arm, single-center trial is evaluating the side effects, best dose, and efficacy of autologous CD8+ SLC45A2 (a membrane-associated melanocyte differentiation antigen)-specific $\mathrm{T}$ lymphocytes, administered along with cyclophosphamide, IL-2, and ipilimumab, in 19 patients with MUM
(NCT03068624). Additionally, a small phase I/II, singlearm, single-center trial, including patients with ocular melanoma, is investigating treatment with non-myeloablative chemotherapy followed by adoptive transfer of autologous T cells modified with a TCR specific for melanoma-associated antigens recognized by $\mathrm{T}$ cells (NCT02654821). There is also an ongoing phase I/II, twoarm, multicenter trial exploring the safety and activity of preferentially expressed antigen in melanoma (PRAME)TCR therapy, which includes a cohort of MUM patients (NCT02743611); autologous T cells (BPX-701) are modified to target the tumor marker PRAME and include a biological safety switch that is controllable with rimiducid. T-cell therapy has also been used to target GD2, a ganglioside expressed across the surface of neuroblastomas, melanoma cells, and other tumor types [38]. The GAIL-N trial is an early phase I, single-arm, single-center study aiming to recruit 64 participants, including MUM patients, to evaluate the largest safe dose, toxicity, and efficacy of autologous T lymphocytes expressing GD2specific chimeric antigen and constitutively active IL7 receptors (GD2-C7R and chimeric antigen receptor [CAR] T cells) to treat GD2-positive solid cancers (NCT03635632).

\section{Bispecific TCR Redirection}

Tebentafusp (IMCgp100) is a potential new therapy designed to treat MUM based on a unique ImmTAC TCR-based bispecific platform. Tebentafusp has a binding region developed to target intracellularly derived melanoma-associated gp100 $280-288$ peptide in complex with human leukocyte antigen (HLA)- $\mathrm{A}^{*} 02: 01$ on the surface of cancer cells. Gp100 is expressed more frequently (100 and $85 \%$, respectively), uniformly, and at higher levels on UM cells compared with CM cells [39]. HLA-A*02:01 is present in approximately $50 \%$ of Caucasian patients [40]; HLA-A $2 * 02: 01$ positivity is an inclusion criterion for patients in tebentafusp clinical trials. Once bound, in clinical studies, tebentafusp recruits a broad range of $\mathrm{T}$ cells (regardless of their specificity) into the tumor via its effector anti-CD3 single-chain variable fragment region, designed to mimic an immune synapse, and activates Tcell-mediated lysis $[2,15,41,42]$; this mechanism is independent of tumor mutational burden.

Clinical activity of tebentafusp was first demonstrated in a phase I, two-arm, multicenter IMCgp100-01 trial evaluating dose, safety, and efficacy (NCT01211262) in both MUM and metastatic CM (MCM); the MUM cohort of 19 patients reported a response rate of $16 \%$, with a 1-year OS rate of $65 \%$ for the overall population of both MCM and 
Table 4. Summary table of key clinical study endpoint data currently available for UM patients in immunotherapy clinical trials [5-7, $15,21,22,24,26,27,33,37,43,44]$

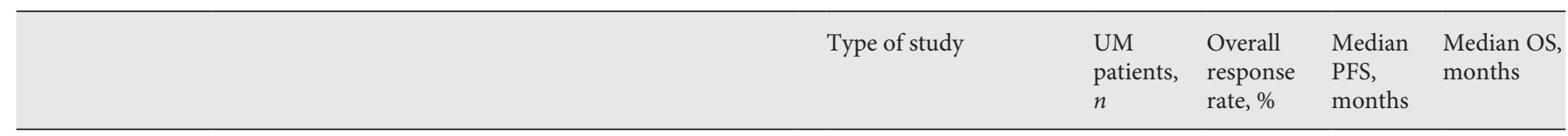

Immune checkpoint inhibition

Monotherapy

Clinical outcomes in MUM treated with PD-1 and PD-L1

antibodies[21]

Prognostic factors and outcomes in MUM treated with PD-1 or combined

PD-1/CTLA-4 inhibition [22]

Nivolumab for patients with MUM previously untreated with ipilimumab:

a single-institution retrospective study [24]

Combination therapy and with other agents

Prognostic factors and outcomes in MUM treated with PD-1 or combined PD-1/CTLA-4 inhibition [22]

Combined immune checkpoint blockade for MUM: a
retrospective, multicenter study [26]
$\begin{aligned} & \text { Ipilimumab + nivolumab for patients with MUM: a multicenter, retrospective } \\ & \text { study [27] }\end{aligned}$

Nivolumab + ipilimumab in previously untreated MUM (GEM1402)

(NCT02626962 [5])

\begin{tabular}{|c|c|c|c|c|c|}
\hline Nivolumab + ipilimumab in MUM (NCT01585194 [6] & Phase II clinical & 30 & 17 & 6.0 & 19.1 \\
\hline $\begin{array}{l}\text { SIR-Spheres Yttrium90 + ipilimumab + nivolumab for MUM (NCT02913417 } \\
\text { [7]) }\end{array}$ & Phase I/II clinical & 13 & 23 & 6.2 & $>11$ \\
\hline $\begin{array}{l}\text { Efficacy study of pembrolizumab with entinostat to treat MUM (PEMDAC) } \\
\text { (NCT02697630 [33]) }\end{array}$ & Phase II clinical & 29 & 10 & $\mathrm{nr}$ & 11.5 \\
\hline
\end{tabular}

TILs

Immunotherapy using TILs for metastatic ocular melanoma

(NCT01814046 [37])

$\begin{array}{lllll}\text { Phase II clinical } & 20 & 35^{\mathrm{a}} & \mathrm{nr} & \mathrm{nr}\end{array}$

Bispecific TCR T-cell redirection - tebentafusp

Tebentafusp (IMCgp100) in MM (NCT01211262 [43])

Intrapatient escalation dosing with tebentafusp (IMCgp100) in MUM patients (NCT02570308 [15, 44])

\begin{tabular}{lccll}
$\begin{array}{l}\text { Retrospective } \\
\text { explorative analysis }\end{array}$ & 56 & 3.6 & 2.6 & 7.7 \\
$\begin{array}{l}\text { Retrospective } \\
\text { explorative analysis }\end{array}$ & 86 & 4.7 & $2.8-3.1$ & $10-14$ \\
\hline $\begin{array}{l}\text { Retrospective } \\
\text { explorative analysis }\end{array}$ & 14 & 7.1 & 2.3 & 13.8 \\
\hline
\end{tabular}

\begin{tabular}{lcccc}
$\begin{array}{l}\text { Retrospective } \\
\text { explorative analysis }\end{array}$ & 15 & 16.7 & 2.8 & $\mathrm{nr}$ \\
$\begin{array}{l}\text { Retrospective } \\
\text { explorative analysis }\end{array}$ & 64 & 15.6 & 3.0 & 16.1 \\
\hline $\begin{array}{l}\text { Retrospective } \\
\text { explorative analysis }\end{array}$ & 89 & 11.6 & 2.7 & 15 \\
\hline $\begin{array}{l}\text { Phase II clinical } \\
\text { Phase II clinical }\end{array}$ & 50 & 12 & 3.3 & 12.7 \\
\hline Phase I/II clinical & 13 & 23 & 6.2 & $>11$ \\
\hline Phase II clinical & 29 & 10 & $\mathrm{nr}$ & 11.5 \\
\hline
\end{tabular}

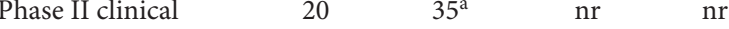

up at 19.1

This table sets forth reported data only, including interim data. Due to the differing nature of each trial design and the lack of head-to-head studies, this table is not intended to present any comparison of treatment agents or effectiveness. The trials in this table are the more meaningful studies involving $>10$ patients. PFS, progression-free survival; OS, overall survival; MM, metastatic melanoma; MUM, metastatic uveal melanoma; nr, not reported; PD-1, programmed death-1; PD-L1, programmed death-ligand 1; TIL, tumor-infiltrating lymphocytes; UM, uveal melanoma; CTLA-4, cytotoxic T-lymphocyte antigen-4; TCR, T-cell receptor. ${ }^{a}$ In terms of objective tumor regression.

MUM patients, with similar survival reported for both MCM and MUM patients [43]. A subsequent phase I/II, two-arm, multicenter study (IMCgp100-102 [NCT02570308]), which only enrolled patients with MUM, demonstrated a response rate of $18 \%$, a median PFS of 5.6 months, median OS not reached after follow-up at 19.1 months, and a 1 -year OS rate of $74 \%$ based on 19 patients from the phase I portion of the study $[2,15,44]$; the phase II expansion in 130 previously treated patients is currently ongoing, but no longer recruiting. Additionally, adverse events have generally been manageable and consistent with the hypothesized mechanism of action for tebentafusp, with most adverse events relating to on-target (gp100) offtumor activity (such as rash, pruritus, or depigmentation), or cytokine-mediated events (such as pyrexia and hypotension) $[2,15,43]$. There is now a pivotal, randomized, two-arm, multicenter controlled study aiming to recruit $>300$ previously untreated MUM patients to compare 
tebentafusp to dacarbazine, ipilimumab, or pembrolizumab monotherapy (IMCgp100-202 [NCT03070392]).

A summary of the key clinical study endpoint data currently available for UM patients in immunotherapy clinical trials, discussed in this review, is presented in Table 4. However, due to the differing nature of each trial design and the lack of head-to-head studies, this table is not intended to present any comparison of treatment agents or effectiveness.

\section{Conclusion}

The race to find an effective and safe immunotherapy to treat UM is underway. Checkpoint inhibition has been beneficial in managing CM and an option to treat UM. However, the low mutational burden and poor immunogenicity of UM tumors may underlie poor responses and resistance to ICIs alone $[19,20]$. Trials investigating combination ICIs, multimodality approaches, novel inhibitors targeting newer checkpoints, vaccine approaches, and adoptive T-cell strategies are ongoing. Pretreatment, on-treatment, and on-progression biopsies have been incorporated into many of the trials discussed. Information gathered from studying these important samples will inform the field about biomarkers, predictors of response, and mechanisms of innate and acquired resistance. Subsequently, this will contribute to a greater understanding of UM biology that may further direct future drug development and clinical trial design. Moreover, continued referral of UM patients for clinical trials is vital for moving the field forward.

\section{Acknowledgements}

During the preparation of this manuscript, medical writing assistance (financially supported by Immunocore Ltd.) was provided by Dr. Lara Sanders of Syneos Health Communications UK Ltd, London, UK. "ImmTAC" is a registered trademark of Immunocore Ltd., Abingdon, UK.

\section{Conflict of Interest Statement}

The funding for this manuscript was initiated by Immunocore Ltd. However, the content represents the views and opinions of the author, Dr. Orloff, with editorial review by Immunocore Ltd. for accuracy. The author has received research support from consulting and speaker fees from Bristol-Myers Squibb. She has received consulting fees, research funding to institution, and contributed to an education campaign www.thinkuvealmelanoma.com, sponsored by Immunocore Ltd.

\section{Author Contributions}

The sole author of this manuscript was Dr. Marlana Orloff, who was involved in all stages of manuscript development and approved the final version.

\section{References}

1 Pandiani C, Béranger GE, Leclerc J, Ballotti R, Bertolotto C. Focus on cutaneous and uveal melanoma specificities. Genes Dev. 2017; 31(8):724-43.

2 Damato BE, Dukes J, Goodall H, Carvajal RD. Tebentafusp: $\mathrm{T}$ cell redirection for the treatment of metastatic uveal melanoma. Cancers (Basel). 2019;11(7):971.

3 Bakhoum MF, Esmaeli B. Molecular characteristics of uveal melanoma: insights from the Cancer Genome Atlas (TCGA) Project. Cancers (Basel). 2019;11(8):1061.

4 National Comprehensive Cancer Network. NSCLC Version 1.2020 [Internet]. [Accessed 2020 Aug 14]. Available from: https://www. nccn.org/professionals/physician_gls/pdf/ uveal.pdf.

5 Piulats Rodriguez JM, De La Cruz Merino L, Espinosa E, Alonso Carrión L, Martin Algarra S, López-Castro R, et al. Phase II multicenter, single arm, open label study of nivolumab in combination with ipilimumab in untreated patients with metastatic uveal melanoma (GEM1402.NCT02626962). Ann Oncol.

Clinical Trials in Metastatic Uveal

Melanoma: Immunotherapy
2018;29(8Suppl):viii442-66.https://doi. org/10.1093/annonc/mdy289.003

6 Pelster M, Gruschkus SK, Bassett R, Gombos DS, Shephard M, Posada L, et al. Phase II study of ipilimumab and nivolumab (ipi/ nivo) in metastatic uveal melanoma (UM). Clin Oncol. 2019;37(15 Suppl):9522.

7 Minor DR, Sato T, Orloff MM, Luke JJ, Eschelman DJ, Gonsalves CF, et al. Initial report of treatment of uveal melanoma with hepatic metastases with yttrium 90 internal radiation followed by ipilimumab and nivolumab. J Clin Oncol. 2020;38(15 Suppl):10025.

8 Khan MK, Nasti T, Masoumy L, Kamphorst AO, Yushak MI, Owonikoko TK, et al. Safety and efficacy of combining pembrolizmumab and dose escalation/fraction de-escalation SRS for melanoma and NSCLC brain metastasis: Preliminary results from arm a of a prospective pilot trial. J Clin Oncol. 2018;36(15 Suppl):e21542.

9 Khan MK, Nasti T, Yushak ML, Lawson DH, Switchenko JM, Wallington D, et al. Interim results of prospective pilot phase II trial of concurrent anti-PD- 1 and stereotactic radiosurgery (SRS) for melanoma and NSCLC patients with brain metastases (NCT02858869). J Clin Oncol. 2020;38(15 Suppl):e22002.

10 Phillips S, Lizee G, Brown C, Lara JM, Bassett RL, Beal LG, et al. A phase Ib study of endogenous SLC45A2-specific cytotoxic T cells for the treatment of patients with metastatic uveal melanoma. J Clin Oncol. 2020;38(15 Suppl):TPS10086.

11 Glitza IC, Rohlfs ML, Iqbal M, Richard J, Burton E, Duncan S, et al. A phase I/Ib study of concurrent intravenous (IV) and intrathecal (IT) nivolumab (Nivo) for melanoma patients (pts) with leptomeningeal disease (LMD). Ann Oncol. 2018;29(8 Suppl): viii442-66.

12 Glitza IC, Phillips S, Brown C, Haymaker CL, Bassett RL, Lee JJ, et al. Single-center phase I/ Ib study of concurrent intrathecal (IT) and intravenous (IV) nivolumab (N) for metastatic melanoma (MM) patients (pts) with leptomeningeal disease (LMD). J Clin Oncol. 2020; 38(15 Suppl): 10008 . 
13 Jespersen $\mathrm{H}$, Olofsson Bagge R, Ullenhag G, Carneiro A, Helgadottir H, Ljuslinder I, et al. Concomitant use of pembrolizumab and entinostat in adult patients with metastatic uveal melanoma (PEMDAC study): Protocol for a multicenter phase II open label study. BMC Cancer. 2019;19(1):415.

14 Bernicker EH, Teh BS, Butler B, Chang JC. Abstract CT064: Trial of SBRT and in-situ gene therapy followed by nivolumab in metastatic non-small cell lung carcinoma (ENSIGN). Cancer Res. 2017;77Suppl)::13CT064. http://dx.doi.org/10.1158/1538-7445. AM2017-CT064.

15 Sato T, Nathan PD, Hernandez-Aya L, Sacco JJ, Orloff MM, Visich J, et al. Redirected T cell lysis in patients with metastatic uveal melanoma with gp100-directed TCR IMCgp100: Overall survival findings. J Clin Oncol. 2018; 36(15 Suppl):9521.

16 Rohaan MW, van den Berg J, Gomez-Eerland $\mathrm{R}$, van Zon M, de Boer R, Bakker EAM, et al. Multicenter phase I/IIa study using T cell receptor gene therapy in metastatic melanoma. J Clin Oncol. 2018;36(15 Suppl):TPS9602.

17 Luke JJ, Flaherty KT, Ribas A, Long GV. Targeted agents and immunotherapies: optimizing outcomes in melanoma. Nat Rev Clin Oncol. 2017;14(8):463-82.

18 Wolchok JD, Chiarion-Sileni V, Gonzalez R, Rutkowski P, Grob JJ, Cowey CL, et al. Overall survival with combined nivolumab and ipilimumab in advanced melanoma. N Engl J Med. 2017;377(14):1345-56.

19 Javed A, Arguello D, Johnston C, Gatalica Z, Orloff MM, Mastrangelo MJ, et al. Disparity in PD-L1 expression between metastatic uveal and cutaneous melanoma. J Clin Oncol. 2016;34(15 Suppl):9541.

20 Sacco JJ, Kalirai H, Kenyani J, Figueiredo CR, Coulson JM, Coupland SE. Recent breakthroughs in metastatic uveal melanoma: a cause for optimism? Future Oncol. 2018; 14(14):1335-8.

21 Algazi AP, Tsai KK, Shoushtari AN, Munhoz RR, Eroglu Z, Piulats JM, et al. Clinical outcomes in metastatic uveal melanoma treated with PD-1 and PD-L1 antibodies. Cancer. 2016;122(21):3344-53.

22 Heppt MV, Heinzerling L, Kähler KC, Forschner A, Kirchberger MC, Loquai C, et al. Prognostic factors and outcomes in metastatic uveal melanoma treated with programmed cell death-1 or combined PD-1/cytotoxic Tlymphocyte antigen-4 inhibition. Eur J Cancer. 2017;82:56-65.

23 Heppt MV, Steeb T, Schlager JG, Rosumeck S, Dressler C, Ruzicka T, et al. Immune checkpoint blockade for unresectable or metastatic uveal melanoma: A systematic review. Cancer Treat Rev. 2017;60:44-52.
24 Namikawa K, Takahashi A, Mori T, Tsutsumida A, Suzuki S, Motoi N, et al. Nivolumab for patients with metastatic uveal melanoma previously untreated with ipilimumab: A single-institution retrospective study. Melanoma Res. 2020;30(1):76-84.

25 Johnson DB, Bao R, Ancell KK, Daniels AB, Wallace D, Sosman JA, et al. Response to antiPD-1 in uveal melanoma without high-volume liver metastasis. J Natl Compr Canc Netw. 2019;17(2):114-7.

26 Heppt MV, Amaral T, Kähler KC, Heinzerling L, Hassel JC, Meissner M, et al. Combined immune checkpoint blockade for metastatic uveal melanoma: A retrospective, multi-center study. J Immunother Cancer. 2019;7(1): 299.

27 Najjar YG, Navrazhina K, Ding F, Bhatia R, Tsai K, Abbate K, et al. Ipilimumab plus nivolumab for patients with metastatic uveal melanoma: A multicenter, retrospective study. J Immunother Cancer. 2020;8(1): e000331.

28 Shoushtari AN, Navid-Azarbaijani P, Friedman CF, Panageas K, Postow MA, Callahan $\mathrm{MK}$, et al. Efficacy of nivolumab and ipilimumab (Nivo + Ipi) combination in melanoma patients (pts) treated at a single institution on an expanded-access program (EAP). J Clin Oncol. 2016;34(15 Suppl):9554.

29 Afzal MZ, Mabaera R, Shirai K. Metastatic uveal melanoma showing durable response to anti-CTLA-4 and anti-PD-1 combination therapy after experiencing progression on anti-PD-1 therapy alone. J Immunother Cancer. 2018;6(1):13.

30 Rodrigues M, Mobuchon L, Houy A, Fiévet A, Gardrat S, Barnhill RL, et al. Outlier response to anti-PD1 in uveal melanoma reveals germline MBD4 mutations in hypermutated tumors. Nat Commun. 2018;9(1):1866.

31 Waight J, Iyer P, Breous-Nystrom E, Riordan C, Findeis M, Underwood D, et al. Abstract 3825: INCAGN02390, a novel antagonist antibody that targets the co-inhibitory receptor TIM-3. Cancer Res. 2018;78(13 Suppl):3825.

32 Durante MA, Rodriguez DA, Kurtenbach S, Kuznetsov JN, Sanchez MI, Decatur CL, et al. Single-cell analysis reveals new evolutionary complexity in uveal melanoma. Nat Commun. 2020;11(1):496.

33 Jespersen $H$, Olofsson Bagge R, Ullenhag G, Carneiro A, Helgadottir H, Ljuslinder I, et al. Phase II multicenter open label study of pembrolizumab and entinostat in adult patients with metastatic uveal melanoma (PEMDAC study). Ann Oncol. 2019;30:v907.
34 Maker AV, Phan GQ, Attia P, Yang JC, Sherry RM, Topalian SL, et al. Tumor regression and autoimmunity in patients treated with cytotoxic $\mathrm{T}$ lymphocyte-associated antigen 4 blockade and interleukin 2: A phase I/II study. Ann Surg Oncol. 2005;12(12):1005-16.

35 Krantz BA, Dave N, Komatsubara KM, Marr BP, Carvajal RD. Uveal melanoma: epidemiology, etiology, and treatment of primary disease. Clin Ophthalmol. 2017;11:279-89.

36 Krishna Y, McCarthy C, Kalirai H, Coupland SE. Inflammatory cell infiltrates in advanced metastatic uveal melanoma. Hum Pathol. 2017;66:159-66.

37 Chandran SS, Somerville RPT, Yang JC, Sherry RM, Klebanoff CA, Goff SL, et al. Treatment of metastatic uveal melanoma with adoptive transfer of tumour-infiltrating lymphocytes: a single-centre, two-stage, singlearm, phase 2 study. Lancet Oncol. 2017;18(6): 792-802.

38 Navid F, Santana VM, Barfield RC. Anti-GD2 antibody therapy for GD2-expressing tumors. Curr Cancer Drug Targets. 2010;10(2): 200-9.

39 TCGA Research Network [Internet]. Available from: https://www.cancer.gov/tcga.

40 The Allele Frequency Net Database [Search HLA Allele Frequencies] [Internet]. [Accessed 2020 Oct 21]. Available from: http:// www.allelefrequencies.net/hla6006a.asp?hla locus_type $=$ Classical\&hla_locus $=\&$ hla allele $1=A^{*} 02 \% 3 \mathrm{~A} 01 \&$ hla_allele $2=\&$ hla selection $=\&$ hla_pop_selection $=\&$ hla population $=1358 \&$ hla_country $=\&$ hla_dataset $=\&$ hla_region $=\&$ hla_ethnic $=\&$ hla_study=\&hla_order=order_1\&hla_s.

41 Oates J, Hassan NJ, Jakobsen BK. ImmTACs for targeted cancer therapy: why, what, how, and which. Mol Immunol. 2015;67(2 Pt A): 67-74.

42 Boudousquie C, Bossi G, Hurst JM, Rygiel KA, Jakobsen BK, Hassan NJ. Polyfunctional response by ImmTAC (IMCgp100) redirected CD8(+) and CD4(+) T cells. Immunology. 2017;152(3):425-38.

43 Middleton MR, McAlpine C, Woodcock VK, Corrie P, Infante JR, Steven NM, et al. Tebentafusp, a TCR/anti-CD3 bispecific fusion protein targeting gp100, potently activated antitumor immune responses in patients with metastatic melanoma. Clin Cancer Res. 2020; 26(22):5869-78.

44 Carvajal R, Sato T, Shoushtari AN, Sacco J, Nathan P, Orloff M, et al. P208: safety, efficacy and biology of the gp100 TCR-based bispecific T cell redirector, IMCgp100 in advanced uveal melanoma in two phase 1 trials. In: SITC. November 8-12. National Harbor, MA, USA; 2017. 